\title{
The role of free iron in cardiovascular diseases. Part II
}

\author{
M Izzo ${ }^{1,4}$, V Gasbarro ${ }^{1,2}$, V Coscia $^{1,3}$ \\ ${ }^{1}$ Research Center "Mathematics for Technology, Medicine and Biosciences", University of Ferrara, Via Saragat 1, \\ 44122 Ferrara \\ 2 Department of Morphology, Surgery and Experimental Medicine, University of Ferrara, Via A. Moro 8, 44124 Ferrara \\ 3 \\ ${ }^{3}$ Department of Mathematics and Computer Science, University of Ferrara, Via Machiavelli 35, 44121 Ferrara \\ (corresponding author, email: vincenzo.coscia@unife.it) \\ ${ }^{4}$ Compression Therapy study Group (CTG)
}

submitted: Oct 20, 2017, accepted: Nov 23, 2017, EPub Ahead of Print: Dec 28, 2017, published: Dec 31, 2017

Conflict of interest: none

DOI: 10.24019/jtavr.35 - Corresponding author: Prof. Vincenzo Coscia, vincenzo.coscia@unife.it, cos@unife.it

(C) 2017 Fondazione Vasculab impresa sociale ONLUS. All rights reserved.

\begin{abstract}
This work is the second part of a review on the role of free iron forms in cardiovascular diseases. Here, we stress on various aspects related to the iron form that are free of poorly chelated to iron biocarriers, as for example the NTBI (Non Transferrin Bound Iron). We report on problems relating the determination of such free iron forms and, after all, on their implications in cardiac diseases as well as in venous insufficiency.
\end{abstract}

Keywords Free and poorly chelated iron; Biocarriers; Cardiovascular diseases; Venous insufficiency

\section{Non-Transferrin Bound Iron}

In the first part $^{1}$ of the review we outlined the role of free iron in vascular diseases. Actually, it is well known that most of the body's iron is bound to the protein and non-protein biomolecules (carriers) in order to render it bioavailable, so as to move it between the various compartments and overcoming the great toxicity that characterize the free iron, due to its ability to create organic bounds, generating oxidative and nitro-oxidative stress. The most relevant iron carrier is the transferrin, while the main iron deposit is the ferritin. In recent years great attention has been paied to the non-transferrin bound iron (NTBI), a form of free iron highly reactive. Such poorly chelated form of iron could play a role in a number of pathologies and cannot depend on a systemic overload condition of iron. This should lead to a reflection since, for example, even in a condition of iron-deficient anaemia it is possible to find such toxic forms of iron released by their transferrin and ferritin carriers.

The non-transferrin bound iron (NTBI) forms, also denote as non-protein bound iron (NPBI), are grouped in different chemical forms with different characteristics. The cytoplasmic labile iron pool (LIP) is involved in the regulation of the cytosolic iron regulatory proteins $(\text { IRP })^{2}$. Further evidences show that there exist unbound forms also for the copper (non-ceruloplasmin bound copper, $\mathrm{NCBC}$ ), that are toxic and relevant in the pathogenesis of neurodegenerative ${ }^{3,4}$ and cardiovascular diseases as well as in the atherogenic process 5 . The term "Labile Iron Plasma, LIP" was coined by Greenberg and Wintrobe in $1946^{6}$. It was then modified by Jacob in 1977 in "Transient Iron Pool, $T I P^{\prime \prime}$, while Kruszewski ${ }^{8}$ refers to it as "Labile Iron Pool, $L I P^{\prime \prime}$, that is, as the poorly chelated iron with low molecular weight that is able to rapidly cross the cells. Some authors 8,9 have also used the term of "catalytic iron pool" to indicate these scarcely bound, highly reactive iron forms, able to set off oxidative stress. Chelation kinetics studies have shown these "iron free" forms starting from the chelators used and, in this way, a number of techniques have been describes, such as:

BDI: bleomycin detectable iron ${ }^{10}$ 
- DCI: desferrioxamina chelable iron, a term used by Breuer to indicate NTBI iron ${ }^{11}$

- BPS: bathophenantroline-disulphonate, a chromogenic chelator detecting the free iron at 532 $\mathrm{nm}^{12}$

In normal conditions, the transferrin is saturated with the iron about at $20-35 \%(20 \mu \mathrm{mol} / \mathrm{L})$, and this represents the main non-Heme circulating iron form. However, the transferrin saturation can increase, ensuring in this way an effective chelating mechanism and neutralizing a possible increase in the iron amount. For this reason, in a healthy individual the circulating NTBI (Non Transferrin Bound Iron) is essentially absent, its plasmatic levels being less than $1 \mathrm{~mol} / \mathrm{L}$, hard to detect by the majority of actual lab methods ${ }^{13}$. In pathologic conditions due to iron overload, such as thalassemia, hemochromatosis etc. ${ }^{14,15}$, a progressive increase in the free NTBI iron content also corresponds to an increased iron saturation of transferrin. While this mechanism is intuitive and explicable ${ }^{16}$ its contrary, that is, normal or little increased levels of transferrinic saturation and increased circulating free iron, is less easy to understand ${ }^{17}$.

For this reason the early studies on NTBI iron were mainly performed in iron overload conditions. Subsequently, and surprisingly, it has been pointed out that even in normal conditions (in absence of iron overload) a non-vanishing part of free NTBI iron can be present. Than, the obvious queston follows: "how it is possible to find iron in its free form even when a formidable chelator as the transferrin is present?" A number of possible answers have been proposed to the above question. However, they appear to be partial, due to the numerous aspects not clearly defined and still object of investigation.

We begin focusing on the following point. The main sources of iron in humans derive from two fundamental mechanisms:

- a) the absorption by the intestinal mucosa (an exogenous food source);

b) the recovery of iron past the lysis of aged erythrocytes and the macrophage activity (an endogenous source).

The average life of red cells is 120 days, During this time, they runs about $300,400 \mathrm{Km}$ and, once aged, they show ever more serious alterations, being eventually destroyed and their components recycled. In this way, the proteins are reused for different scopes, the iron is disassembled and reused by other cells to build red cells or any other molecules that require it. The released heme is degraded by the heme-oxygenase microsomal enzymatic system, that requires oxygen and NADPH and finally ends as bilirubin that enters the bowel and performs a function in the food digestion. The endogenous source of iron deriving from the previously described erythrolysis mechanisms is more relevant with respect to the exogenous one, as for the latter one the control and the absorption by the intestinal mucose is particularly selective and finely tuned.

As an example, in case of hemolitic anemia or of transfusion, the excess of erythrocyte lysis determines an increase of iron that binds its chelator, the transferrin, causing an increase of its saturation index and, at the same time, releasing a certain amount of free NTBI iron $^{18}$. In different conditions, as for example in absence of transferrin, the circulating levels of NTBI iron can reach values of $20 \mu \mathrm{mol} / \mathrm{L}$, while when the transferrin is present but in reduced quantity the previous values are, in general, less than $10 \mu \mathrm{mol} / \mathrm{L}^{19}$. It is well known that the iron is able to lead to an oxidative stress; on the other hand, the oxidative stress can release free NTBI iron from different sources like the "iron sulphur proteins", ferritin, hemoglobin, etc., as it has long been reported in the literature ${ }^{20-23}$, and this observation should induce to reflection. In summary, the sources of free NTBI iron can be generated in different pathologic conditions in which to the availability of high level of iron but also when the levels of transferrin iron saturation are normal or low, as consequence of oxidative stress. In fact, during the oxidative stress, an amount of iron can also be released by stable sources (ferritin, heme), triggering a vicious circle $^{24,25}$.

In Table I we report some pathologic conditions in which circulating forms of free, unchelated iron are observed $^{26}$ :

In Table I it can be noticed that the higher free iron concentrations are not revealed in the hereditary hemochromatosis, as it could be expected, but in the cancer in course of chemotherapy ${ }^{27}$. Due to its cation nature, the iron easily binds to anion substrates giving rise to a number of new chemical compounds grouped, as already stated, under the denomination of non transferrin bound iron (NTBI). To the best of present knowledge, among all these substances in which the iron is readily available, the most frequent and dangerous are exactly those generated by the cation iron, like albumin, citrate, acetate, phosphate, etc. For example, in the hemochromatosis the more abundant form of NTBI if that one bound to citrate and acetate ${ }^{28}$, the other form being that one bound to albumin (anion protein) also in conditions of transferrin poorly satured of iron $^{29}$. These isoforms of NTBI iron ${ }^{30}$ in which the $\mathrm{Fe}^{3+}$ is mainly bound to citrate and to albumines and, potentially, also to acetate, malate and phosphate, also increase the risk of infection $^{31}$ (indeed, it is known that the iron is used by bacteria, fungi etc. to improve their replication), as well as the toxicity due to the endocellular overload of NTBI that, 
since has not the fine tuning mechanisms mediated by the transferrin, is able to directly enter the cell ${ }^{32}$.

\begin{tabular}{|c|c|c|}
\hline Pathology & $\begin{array}{l}\text { Free iron } \\
\text { form }\end{array}$ & $\begin{array}{l}\text { Concentration } \\
((\mu \mathrm{mol} / \mathrm{l})\end{array}$ \\
\hline $\begin{array}{l}\text { Hereditary } \\
\text { hemochromatosis }\end{array}$ & NTBI & $4.0-16.3$ \\
\hline $\begin{array}{l}\text { Thalassemia } \\
\text { major }\end{array}$ & DCI & $1.7-8.6$ \\
\hline Diabetes mellitus & NTBI & $0.62 \pm 0.43$ \\
\hline $\begin{array}{l}\text { Severe renal } \\
\text { impairment }\end{array}$ & NTBI & $0.1-13.5$ \\
\hline $\begin{array}{l}\text { Cancer in course } \\
\text { of chemotherapy }\end{array}$ & NPBI & $10.6 \pm 6.6$ \\
\hline \multicolumn{3}{|c|}{$\begin{array}{l}\text { Table I - Pathologies and corresponding observed free } \\
\text { iron forms (after Patel M, 2012, modified). NTBI- } \\
\text { Non Transferrin Bound Iron, DCI - Desferrioxamine- } \\
\text { chelatable iron, NPBI - Non Protein Bound Iron. }\end{array}$} \\
\hline
\end{tabular}

\section{Modalities and problems related to NTBI iron determination}

As previously discussed, it is clear that the NTBI iron forms that are not stably bound to carriers (transferrin, ferritin, heme, etc.) are numerous and probably not yet completely known. As a consequence, the methods used for their determination are correspondingly numerous and constantly updated. Basically, the techniques used are the following:

- 1 - Inductive estimate or dosing, based on the use of glycopeptide antibiotics like the bleomycin used in oncology (10) (bleomycin detectable iron, $\mathrm{BDI})$. In presence of iron, the bleomycin is able to degrade DNA, producing free radicals. By a complex method, introduced for the first time by Gutteridge et al. ${ }^{33}$, it is possible to dose the iron not bound to transferrin.

2- Dosing by the use of different chelator agents, followed by the separation and dosing of the iron by analytic techniques (HPLC, atomic absorption, spectroscopy, etc.). During the years, different chelating agents have been used such as:

EDTA (ethylenediaminetetraacetic acid ) Hershko and coworkers, $1978^{34,35}$

- $\quad$ NTA (unsaturated transferrin) ${ }^{36}$

- DCI: desferrioxamina chelable iron ${ }^{11}$

- $\quad$ BPS: bathophenantroline-disulphonate, a chromogenic chelator able to detect free iron at $532 \mathrm{~nm}^{12}$, etc.
3- Direct dosing of NTBI iron by fluorescence techniques, that are the most recent methods also with the help of siderophores like the azobactin ${ }^{37}$ and those that are currently being used as routine ${ }^{38,39}$. The world's leading experts gathered on 2005 and on 2016 to compare the different techniques in view of their validation and standardization ${ }^{40,41}$. Despite a little preference for the fluorescence, an agreement has not yet reached towards the methods to be used as standard. In the last meeting ${ }^{41} 60$ samples extracted from patients affected by systemic iron overload (hemochromatosis, thalassemia, transfusion patients, etc.) have been sent to five labs all over the world and ten different laboratory kits have been tested for the determination of iron NTBI and LIP, without reaching, as we already said, an unique view, with an exception to be noticed, that is, the transferrin saturation index, that revealed to be the parameter in the best correlation to the possible presence of circulating NTBILIP iron. These researches are obviously performed on patients affected by systemic iron overload, that is, with transferrin highly saturated by iron, and not in pathologies with normal transferrin saturation, though in the literature ${ }^{42}$ the presence of NTBI-LIP has been pointed out also in these circumstances. The iron that is not stably bound to its main carrier (the transferrin) represents a challenge to the different anti-oxidative mechanisms. Such NTBI iron enhances the oxidative stress mainly through the already cited Fenton and Haber-Weiss reactions (Figure 1): with an increase of the oxidative action via the different radicals that are produced (hydroxy, hydrogen peroxide, superoxide, hypoalose acids, etc.).

\section{$\mathrm{Fe}^{2+}+\mathrm{H}_{2} \mathrm{O}_{2} \rightarrow \mathrm{Fe}^{3+}+\mathrm{HO}^{--}+\mathrm{HO}^{-}$ (Fenton reaction) $\mathrm{O}^{2-+}+\mathrm{H}_{2} \mathrm{O}_{2} \rightarrow \mathrm{O}^{2+}+\mathrm{HO}^{--}+\mathrm{HO}^{-}$ (Haber-Weiss reaction) $\mathrm{O}^{2-+} \mathrm{Fe}^{3+} \rightarrow \mathrm{O}_{2}+\mathrm{Fe}^{2+}$}

Figure 1 - Fenton and Haber-Weiss reactions.

\section{Iron and free iron fraction in cardiovascular pathologies}

One of the early remarks on the relation between iron and cardiovascular pathologies was made by Sullivan ${ }^{43}$ on 1981. He pointed out how the lesser amount of iron deposits (ferritin, etc.) in menopause and post-menopausal women plays a protective role, as well as regular phlebotomy appears to do. Another randomized study shows, during an observation period of 5 years in a sample of 1931 subjects, the greater incidence (2.2 times) of myocardial infarction in patients with a ferritin level $>200 \mu \mathrm{g} / \mathrm{l}$ with respect to those 
with a level $<200 \mu \mathrm{g} / \mathrm{l}$. A different work ${ }^{45}$ points out, during a period of 6.4 years in a sample of 99 men, that subjects with low values of the ratio transferrin plasmatic receptor $(t f r) /$ ferritin (that means large iron deposits) present a risk of myocardial infarction 2-3 times higher with respect to subjects with a larger tfr/ferritin ratio (Figure 2):

\section{tfr/ferritin low $\rightarrow$ high iron deposits (iron storage)}

\section{tfr/ferritin high $\rightarrow$ low iron deposits (iron storage)}

Figure 2 - Relation between transferrin plasmatic receptor/ ferritin ratio and iron storage.

Many works demonstrate the relation existing among iron and atherogenic progression.

- $\quad$ In the famous Brunico study ${ }^{[\mathrm{i}]}$, five-years long with a randomized sample of 125 men and 125 women age 40-79 years and a participation in the trial of $93.6 \%$, a strong correlation between carotid asymptomatic atherosclerosis and iron deposits increase (particularly with a ferritin level $>50 \mu \mathrm{g} / \mathrm{L}$ ) is proven ${ }^{46,47}$ In $^{48}$ it is proved that in patients with end stage renal disease receiving an iron supply, is observed a thickening of the intima in the common carotid larger than in subjects that did not receive such a supply.

- A number of independent studies ${ }^{49,50}$ show that in blood donors to low iron deposits levels correspond a lesser incidence of cardiovascular pathologies.

- The work ${ }^{51}$ confirms a clear correlation in healthy individuals between the amount of iron deposits (iron storage) and asymptomatic carotid atherosclerosis studied by the ratio $\mathrm{tfr} /$ ferritin.

- $\quad \operatorname{In}^{52}$ (it is shown that chelation in patient affected by cardiovascular diseases is associated to an improvement of the endothelial function.

- $\quad$ The study ${ }^{53}$ clarifies the relation between the iron food content and the coronary risk in a followup of 4 years and a cohort of 44933 men without any history of cardiovascular pathology, demonstrating the causal implication not so much with the iron quantity introduced with the food as with the heme iron content and the ferritin. Recently, in a metaanalysis of 21 valid studies Hunnicutt ${ }^{54}$ remarks the correlation among dietary iron, iron storage and coronary risk. The dietary iron considered in the finnish work by Salonen ${ }^{55}$ appears to be correlated in a significant way to the coronary disease. The author reports that an increase of $1.0 \mathrm{mg}$ of dietary iron corresponds to an increase of $5 \%$ of the coronary risk. The heme iron contained in the meat (myoglobin and hemoglobin iron) represents about the $40 \%$ of the food iron and, thanks to its high bioavailability 56 its absorption is not inhibited with the negative feedback by the high levels of circulating ferritin, as happens to non-heme iron (inorganic iron) ${ }^{57}$. Nonheme iron can also be found in meat, lever, egg yolk, vegetables, etc. and is present both as $\mathrm{Fe}^{2+}$ and $\mathrm{Fe}^{3+}$ form. Recently, Wolk ${ }^{58}$ proved by meta-analysis a significant increase of cardiovascular mortality after daily intake of $50 \mathrm{~g}$ meat, as already observed by Micha ${ }^{59}$ in relation with treated meat compared with fresh ones.

- Another point worth of attention is that all agents which inhibit the dietary absorption of iron (polyphenols, soy, casein, whey, chicken egg albumen, etc.) affect non-HEME iron only. Furthermore, adding Calcium does not affect the absorption of neither HEME nor non-HEME ${ }^{60}$ iron, in spite of what has been reported during previous studies (Figure 3).

- $\quad$ According to some authors ${ }^{61}$ exercising can in many ways play a major role in iron excretion.

- Some studies show that there is a correlation between cardiovascular conditions and iron ${ }^{62-65}$.

- Very interesting experimental studies ${ }^{66-68}$ show that adding NTBI iron to cultures of human endothelial cells increases the expression of VCAM 1 (Vascular Cell Adhesion Molecule, etc.) as well as leucocyte rolling and endothelial barrier damage. This phenomenon can be stopped by adding iron chelating agents (desferrioxiamine, dipirydyl) to the cultures of human endothelial cells ${ }^{67}$, as it is also confirmed by another study on endothelial cells in the human aorta ${ }^{68}$.

There are more studies confirming the correlation between iron and cardiovascular condition compared to those which deny it ${ }^{68-71}$, and albeit scientists are still divided concerning this topic, it is necessary to highlight that many of the studies which refused this correlation have been carried out with inappropriate techniques and indicators.

More recent studies ${ }^{72}$ verified that NTBI can play a major role in terms of cardio toxicity in myocardial infractions (STEMI: ST evaluation acute myocardial infraction), especially as far as MVO (Micro Vascular Obstructions) and HEM (Hemorrhage) are concerned, the latter being a source of NTBI. 
Food that increase the dietary absorption of iron:

Phytates (cereals, wheat); Polyphenols (fruit, vegetables, cereals, legumes, tea, coffee, wine); Soy; Chicken egg albumen

\author{
Food that decrease the dietary absorption of iron: \\ Ascorbic acid (fruit, vegetables, etc.) ; Muscle proteins (pork, \\ beef, chicken, fish)
}

Figure 3 - Food causing increase or decrease of dietary iron absorption.

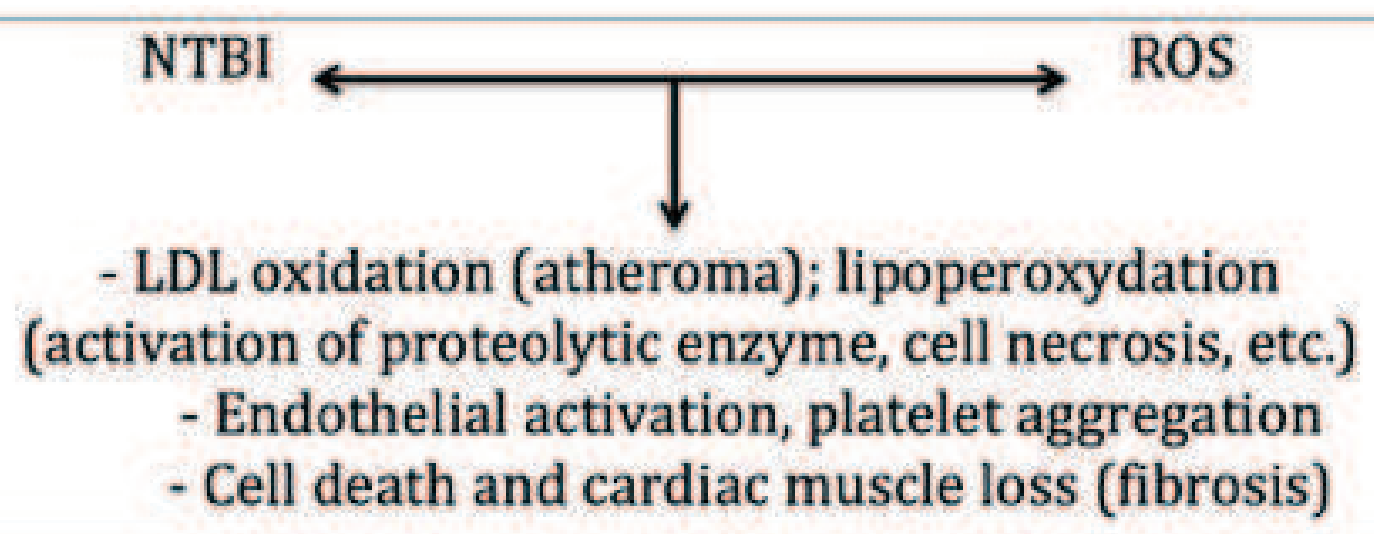

Figure 4 - Cardiovascular toxicity of NTBI iron.

This study points out the close ties between NTBI, CK-MB and troponin; even though the number of patients was rather scarce, such a correlation will definitely be the object of more and more thorough studies.

The study FeAST highlights that even chronic obstructive arterial disease in lower limbs is correlated with iron ${ }^{73}$; furthermore other randomized experiments point out that the mere phlebotomy significantly reduced the mortality rate (myocardial infraction, stroke) among patients suffering from chronic obstructive arterial disease in lower limbs ${ }^{74}$.

The cardiovascular toxicity of NTBI can be summed up as in Figure 4.

In one of his most recent papers ${ }^{75}$, Brissot highlights that even though there is not yet full knowledge of every factor able to produce NTBI, a major role is played by the iron loss in the transferrin-ferritin, by a poor iron re-usage during the erythrocyte lysis and, even more alarmingly, by the condition of chronic oxidative stress.
Other authors ${ }^{76,77}$ highlight that NTBI is a valid marker as far as biological damage is concerned, and not only in iron overload syndromes.

The main factor which regulates the iron output of a cell is the ferroportin under the effect of plasma hepcidin; therefore, low levels of hepcidin can trigger high level of transferrin saturation and NTBI iron, which is easily absorbed by the cells.

Recently Riško ${ }^{77}$ shows that patients with chronic cardiovascular conditions (myocardial infraction, stroke, peripheral obstructive arterial disease) present monocytes free iron-LIP concentration higher than usual; such an anomaly is statistically correlated to the following parameters:

- TfR/F (ratio: circulating transferrin receptor/ ferritin)

- Hepcidin plasma values

- Visceral fat (insulin-resistance)

- ABI index (Ankle-Brachial Index or Winsor index, i.e. an index used in obstructive arterial disease in lower limbs) 
- $\quad$ Arterial stiffness (Pulsatility Index (PI) and Resistance Index (RI))

Such parameters, therefore, highlight the possibility that the intra-monocyte LIP (Labile Iron Pool) can be a sensitive index of the risk of atheroma formation.

Nevertheless, it is important to remark that though the lack of iron is related to cardiovascular disease, the study $\mathrm{ARIC}^{78}$ on anemic patients show that "virtue stands in the middle". The ratio of body iron concentration and risk of occurrence of cardiovascular condition is not linear; on the contrary, it can be described as a U-shaped curve ${ }^{79}$.

\section{Iron, iron-free and atherosclerosis}

Over the past 30-40 years many studies $5,24,42,46,48,51,62,66,67,77,78$ highlighted how the iron mediated oxidative stress played a major role in the formation of the atherosclerosis, also recently mentioning the toxicity of hemoglobin-free ( $\mathrm{Hb}$-free) and its iron content derived from erythrocyte lysis ${ }^{79}$.

For years the iron-induced oxidative stress was considered to be the main pathogenic trigger of atherosclerosis. Today, however, it is known that the factors that trigger the formation of atheroma are many and complex $^{80}$, as far as iron and NTBI are concerned.

Specifically, hydroxyl radicals oxidize lipids and proteins, causing endothelial dysfunctions, cell proliferation (activation of monocytes- macrophages), DNA and immune system damage.

The oxidation of the low density lipoprotein (LDL) is a focal point in the formation of atheroma.

The reactive oxygen species (ROS) can alter the triglyceride fatty acid chains, especially the unsaturated ones, cholesterol esters, and protein structures with formation of Malondialdehyde (MDA) peroxides or hydroxides, pentanes, etc., the oxidation output of the cholesterol, i.e. oxysterols deriving from phospholipids, the alteration of apolipoprotein into carbonyls or amino acids (cysteine, cysteine, histidine, etc.), the formation of lipidsprotein structures known as lipofuscin ${ }^{81}$.

Chemical analysis of lipofuscin samples shows the presence of protein (20-50\%) and lipid (30-70\%) components. The protein component can vary, whereas the lipid component is composed by triglycerides, saturated fatty acids, cholesterol, phospholipids carbohydrates and metals, especially iron ${ }^{82}$.

The LDL oxidation represents a crucial moment in the process of the formation of atheroma, triggering:

- 1 endothelial activation and dysfunction;

- 2 macrophages activation and transformation into foam cells;
- 3 adaptive modification in the immune response.

Most of the studies on the LDL oxidation (Ox-LDL) reported in vitro experiments where pro-oxidizing agents, such as iron, were used. So far scientists are not certain that the LDL oxidation occurs mainly on arterial walls, even though this is almost always the case for patients suffering from diabetes or cardiovascular diseases ${ }^{83}$. Moreover, the LDL oxidation appears to be correlated to the rise of the Creactive protein $(\mathrm{CRP})^{84}$.

It appears that the endothelial dysfunction triggers the cell adhesion molecule (I-CAM 1 or E-Selectine); as a result, the circulation monocytes are then divided in two groups, one composed by the monocytes trapped in the endothelium and the other one by the monocytes which flew through the sub-endothelial space. This grouping takes place under the effect of cytokines such as MCSF (Macrophage Colony Stimulating Factors, produced by macrophages themselves), endothelium cells and $\mathrm{T}$ lymphocytes, macrophages, specifically macrophages M1 (pro-inflammatory) rather than M2 (anti-inflammatory) ${ }^{84}$.

Macrophages M1 express Ox-LDL receptors on their surface for Ox-LDL that, once absorbed, turn the macrophages into foam cells due to the accumulation of cholesterol esters, etc. This macrophage population would also be the cause of both the proliferation of smooth muscle cells that migrate towards the arterial endothelium, and of the atheroma instability due to the activation of metalloproteinase 1,3,9 (MMP 1-3-9) with hydrolysis of the collagen in the atheroma fibrous cap ${ }^{85,86}$.

M2 macrophages have opposite tasks compared to the M1, and are also able to trigger several metalloproteinase (MMP 9-12-13-14) that are important in the re-shaping of the atheroma. Compared to M1 macrophages, M2 macrophages have a lower iron concentration 87 . In addition, chelating substances, such as the lactoferrin, can play a protective role ${ }^{88}$; furthermore, the M1 activation can be directly induced by iron ${ }^{89}$.

Another factor that has recently been studied is the red blood cells phagocytosis in hemorrhage areas, specifically in atheroma ${ }^{90}$. This phenomenon is an important factor determining iron accumulation in Mhem macrophages that have features similar to the M2 macrophages (protective) $^{91,92}$. These HEME filled macrophages also present high HMOX1 levels (heme oxygenase-1, an enzymatic form which, contrarily to HMOX2, is inducible) that can trigger M1 macrophages (pro-inflammatory).

The heme oxygenase is an oxidoreductase that catalyzes the transformation of the heme into biliverdin, carbon monoxide and iron. Thanks to the biliverdin 
reductase, the biliverdin is later on transformed into bilirubin. The iron released induces the expression of the intracellular apoferritin with iron sequestration from the ferritin and iron redox reduction, as a result of the protective effect of the ferritin.

The heme oxygenase appears to play a crucial role in the cellular iron metabolism regulation; furthermore, it is an enzyme that can be induced by many factors such as oxidative stress, inflammation, reperfusion, etc. It is worth being noted, however, that free heme can directly activate M1 macrophages by interacting with Toll-like receptors expressed by many cells (monocytes, macrophages, mast cells, etc.), TLR4 (Toll-like Receptor 4) and innate immunity cells. Contrarily to HMOX2, the enzyme HMOX1, (heme oxygenase 2) is an inducible stress enzyme and its oxidoreductase regulates vascular activity and prevents inflammation and formation of atheroma ${ }^{93}$.

As a matter of fact, HMOX1 polymorphism or deficiencies can be linked to the occurrence of many diseases, especially atherosclerosis, cardiovascular disease, etc. $^{94,95}$.

Another study ${ }^{96}$ shows that the iron contained in the atheroma is a risk factor which can be modified as far as the formation of atheroma plaques is concerned.

\section{Iron and free iron in the chronic venous insufficiency}

In the advanced stages of chronic venous disease that can be considered as insufficiency (CEAP Classification: C3-6) ${ }^{97,98}$ after the occurrence of edema (venous edema, CEAP: C3) a progressive tissue dystrophy takes place, usually evolving to ulcers. This kind of dystrophy is named lipodermatosclerosis (LDS, CEAP: C4b) and it is characterized by the progressive accumulation of hemosiderin iron in dermis and hypodermis. Legs undergo a hyper pigment production and hardening transformation, known as "inverted champagne bottle leg". Lipodermatosclerosis was initially described in 1955 by Huriez as Hypodermitis sclerodermiformis ${ }^{99}$, and later on many other authors denoted this condition by different names (liposclerosis, sclerosing panniculitis, lipomembranous panniculitis associated to venous stasis, etc.). However, this condition is today known in the scientific literature with the name of Lipodermatosclerosis (LDS).

The inferior limbs' chronic venous stasis triggers ambulatory venous hypertension and, finally, ends up rising the transmural pressure, with the appearance of erythrocyte extravasation (extravascular hemolysis) ${ }^{100-102}$ which is also cause of the local hemosiderosis ${ }^{103}$ due to hemosiderosis-iron overload.
More recent studies ${ }^{104-107}$ have progressively showed and clarified that the hemosiderosis-iron overload levels reach their peak in the chronic phase of the lipodermatosclerosis, especially subcutaneously, and then fall due to a progressive fibrotic substitution. Other studies where MRI was used ${ }^{108}$ demonstrated the progressive reduction of subcutaneous fat and its peculiar "honeycomb pattern". The necrosis appears to affect both the adipose lobe and the inter-adipocitary septum (lobe-septum necrosis); the iron can directly trigger lipolysis due to the oxidative stress $^{109}$.

The hyperpigmentation occurring in lipodermatosclerosis has some distinctive points:

- melanine accumulates both in the stratum basale and in the dermis; melanocytes migrate towards the dermis ${ }^{110}$;

- hemosiderin sediments in dermis and hypoderm $^{107,111}(107,111)$;

- melanocyte melanin synthesis appears to be secondary to iron overload and triggered by oxidative stress and iron mediated oxidative stress ${ }^{12-114}$;

- melanin acts like a powerful iron chelating agent $^{115,116}$ and the melanocyte migration towards the dermis might be due to the melanin chelating activity (biological defense strategy).

The correlation between the iron overload in tissues and venous ulcers in the lower limbs was reported for the first time by Ackerman in $1988^{117}$, which observed that the consistent iron hyper overload in the ulcerated tissues was about 10 to 15 times higher compared to the same area in the counter lateral limb.

The presence of hemosiderinuria ${ }^{118}$ is later reported in advanced dystrophic-ulcerative stages of chronic venous insufficiencies and, later on, in other disorders such as lymphedema, connective tissue disease, but not in ischemic ulcers $^{119}$.

Other authors ${ }^{120}$ highlight that iron is present in the ulcer fluid taken from chronic ulcers in lower limbs, but not in that extracted from acute ulcers.

Further studies highlight the relation between tissue iron overload and venous ulcers and some HFE polymorphism (hemochromatosis gene) $)^{121-125}$ and also provided therapy evidence by using topical chelating agents which fasten the venous ulcer healing process ${ }^{126,127}$. Some authors ${ }^{128}$ used the PIXE (Proton Induced X-ray Emission Spectroscopy) to highlight that the iron concentration rises with the evolution of the disease; in fact, the iron deposition rate is higher in incompetent veins compared to competent veins (surgically collected veins); this rate is statistically 
correlated to oxidative stress parameters and to the ratio intima-media. The conclusions of these studies are that the dosage of the PIXE iron can be correlated to the evolution of the insufficiency.

Ferritin and hemosiderin represent the main ways iron can sediment; they differ each other as follows:

- hemosiderin is not water-soluble, but undergoes denaturation;

- ferritin is water-soluble but is temperature resistant up to $75^{\circ} \mathrm{C}\left(167^{\circ} \mathrm{F}\right)$.

Hemosiderin iron is stored in the internal part of the protein shell, especially in the form of ferric hydroxide $\left(\mathrm{Fe}(\mathrm{OH})_{3}\right)$ as a consequence of its degradation and lysosome polymerization $^{129}$. Ferritin is normally the predominant way in which iron is stored in the tissues; hemosiderin, however, can become the predominant form in case of iron overload, causing biological damage ${ }^{130}$ (Figure 5).

In fact the hemosiderin, especially in acid conditions (inflammation, ischemia), can release iron enhancing oxidative stress. When these conditions occur, the hemosiderin can turn itself from iron chelating agent to an iron releasing agent in the form of sediment:

For example, iron can sediment due to erythrocyte extravasation (erytrhodiapedesis, hemolysis related causes,

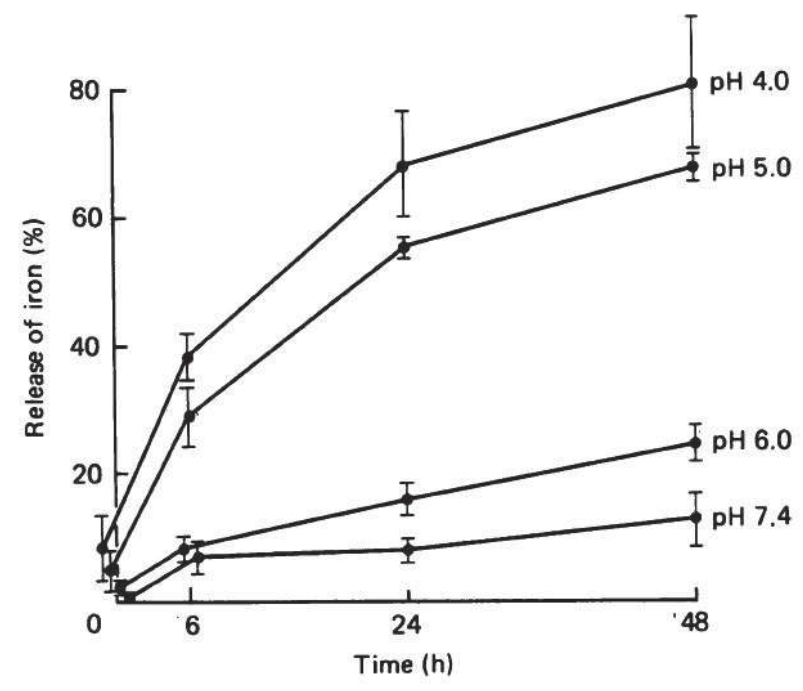

Figure 5 - Iron release vs time (Ozaki 1988, with permission).

\section{Conclusions}

Many authors studied the whole literature concerning the relation between iron accumulation and the increased occurrence of cardiovascular diseases ${ }^{139}$; even though this topic is still under discussion, the new techniques in etc.) both in ferritin and hemosiderin (Figure 6). Moreover, iron can be directly be mobilized by hemosiderin or ferritin $^{130-134}$.

An interesting study on animals ${ }^{135}$ was led by inducing skin iron overload in three different ways (HFE mutation i.e. hemochromatosis, dietary iron overload, direct iron injection); the results of the study highlight that the direct iron injection is the most harmful of the three.

Another study ${ }^{136}$ highlights the direct correlation between the stage of skin exfoliation (dyskeratosis) and the level of iron in the skin. Yet another study analyses the toxic effects derived from iron overload in many diseases, including connective tissue disease (Lupus, rheumatoid arthritis) ${ }^{137}$ and in the wound healing process.

Finally, a biopsy study ${ }^{138}$ was led on many cases of lower limb dermatitis (lichenoid, tinea, chronic venous stasis, folliculitis, psoriasis, etc.) where the Gomori test was used to determine the iron levels in the tissues; the results of the test were positive in $42 \%$ of the cases, thus highlighting the role iron plays in many chronic inflammatory skin disease.

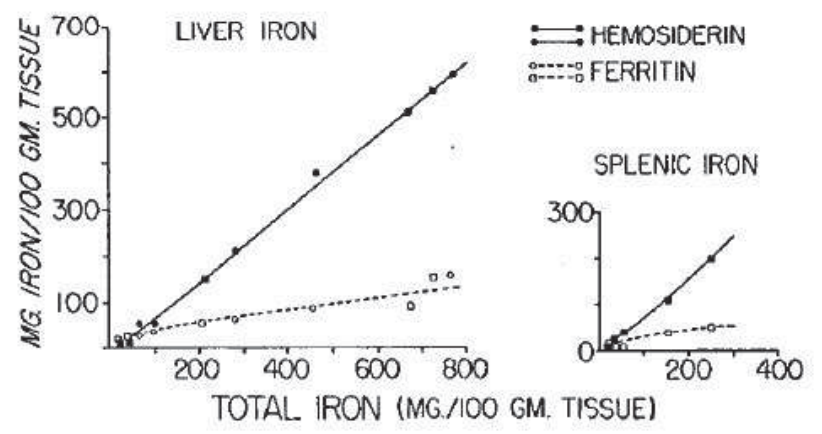

Figure 6 - Iron forms vs total tissue iron content (Shoden 1953, (c) the American Society for Biochemistry and Molecular Biology).

the dosage of free NTBI highlighted the role played by free hemoglobin and HMOX1 (heme oxygenase) in the regulation of the cellular iron and the inducing effect of some drugs on the HMOX1, such as statins, aspirin and more particularly lansoprazole, etc. ${ }^{140,141}$, their protective effect in the vessel endothelium ${ }^{142}$ and, lastly, the challenge 
of the chelating therapy in local siderosis ${ }^{143}$; all of the abovementioned factors seem to corroborate the hypothesis that the iron overload is toxic in cardiovascular diseases.

\section{Endnotes}

[i] Brunico (Bruneck) in the province of Bolzano (Bozen), Italy, at the border between Italy and Austria.

\section{References}

1) Izzo M, Gasbarro V, Coscia V. The role of free iron in cardiovascular diseases - Part I. J. Theor. Appl. Vascular Res. 2017;2(1):21-25

2) Kühn LC. Iron regulatory proteins and their role in controlling iron metabolism. Metallomics. 2015;7(2):232-43.

3) Squitti R, Simonelli I, Ventriglia M, et al. Meta-analysis of serum non-ceruloplasmin copper in Alzheimer's disease. J Alzheimers Dis. 2014;38(4):809-22.

4) Greenough MA, Ramírez Munoz A, Bush AI et al. Metallopathways to Alzheimer's disease: lessons from genetic disorders of copper trafficking. Metallomics. 2016;8:831-839.

5) Riško P, Pláteník J, Buchal R et al. The labile iron pool in monocytes reflects the activity of the atherosclerotic process in men with chronic cardiovascular disease. Physiol Res. 2017; 31;66(1):49-61.

6) Greenberg GR, Wintrobe MM. A labile iron pool. J Biol Chem. 1946;165(1):397. $4331-4336$

7) Jacobs A. An intracellular transit iron pool. Blood, 1977,50,

8) Kruszewski M. Labile iron pool: the main determinant of cellular response to oxidative stress. Mutat Res. 2003;531:81-92.

9) Kakhlon O, Cabantchik ZI. The labile iron pool: characterization, measurement, and participation in cellular processes. Free Rad Biol Med. 2002;33:1037-46.

10) von Bonsdorff $\mathrm{L}$, Lindeberg $\mathrm{E}$, Sahlstedt L, Lehto J, Parkkinen J. Bleomycin-detectable iron assay for non-transferrinbound iron in hematologic malignancies. Clin Chem. 2002;48:307-14.

11) Breuer W, Ermers MJ, Pootrakul P, Abramov A, Hershko C, Cabantchik ZI. Desferrioxamine-chelatable iron, a component of serum non-transferrin-bound iron used for assessing chelation therapy. Blood. 2001;97:792-8.

12) Nilsson UA, Bassen M, Savman K, Kjellmer I. A simple and rapid method for the determination of "free" iron in biological fluids. Free Radic Res. 2002;36:677-84.

13) Anderson GJ. Non-transferrin-bound iron and cellular toxicity. J Gastroenterol Hepatol. 1999;14(2):105-8.

14) Graham G, Bates GW, Rachmilewitz EA, Hershko C. Non-specific serum iron in thalassaemia: quantitation and chemical reactivity. Am J Hematol. 1979;6:207-17.

15) Batey RG, Lai Chung Fong P, Shamir S, Sherlock S. A nontransferrin-bound serum iron in idiopathic hemochromatosis.Dig Dis Sci. 1980;25:340-6.

16) Loréal O, Gosriwatana I, Guyader D, Porter J, Brissot $P$, Hider RC. Determination of non-transferrin-bound iron in genetic
Chronic venous insufficiency is an ideal case to be investigated by studying NTBI as the hemosiderin deposition is very consistent. hemochromatosis using a new HPLC-based method. J Hepatol. 2000;32:727-33.

17) Gosriwatana I, Loréal O, Lu S, Brissot P, Porter J, Hider RC. Quantification of non-transferrin-bound iron in the presence of unsaturated transferrin. Anal Biochem. 1999;273:212-20.

18) Porter JB, Abeysinghe RD, Marshall L, Hider RC, Singh S. Kinetics of removal and reappearance of nontransferrin-bound plasma iron with deferoxamine therapy. Blood. 1996;88:705-13.

19) Anderson GJ. Non-transferrin-bound iron and cellular toxicity.J Gastroenterol Hepatol. 1999;14(2):105-8.

20) Brazzolotto X, Gaillard J, Pantopoulos K, Hentze MW, Moulis JM. Human cytoplasmic aconitase (iron regulatory protein 1) is converted into its [3Fe-4S] form by hydrogen peroxide in vitro but is not activated for iron-responsive element binding. J Biol Chem. $1999 ; 274: 21625-30$.

21) Biemond P, Van Eijk HG, Swaak AJG, Koster JF. Iron mobilization from ferritin by superoxide derived from stimulated polymorphonuclear leukocytes: possible mechanism in inflammatory diseases. J Clin Invest. 1984;73:1576-9.

22) Gutteridge JMC. Iron promoters of the Fenton reaction and lipid peroxidation can be released from haemoglobin by peroxides. FEBS Lett. 1986;201:291-5.

23) Puppo A, Halliwell B. Formation of hydroxyl radicals from hydrogen peroxide in the presence of iron: Is haemoglobin a biological Fenton catalyst? Biochem J. 1988;249:185-90.

24) Chau L. Iron and atherosclerosis. Proceedings of the national science council, Republic of China-Part B. Life Sci. 2000;24: 151-5.

25) Horwitz L, Rosenthal E. Iron-mediated cardiovascular injury. Vasc Med. 1999;4:93-9.

26) Patel M, Ramavataram D.V.S.S. Non Transferrin Bound Iron: Nature, Manifestations and Analytical Approaches for Estimation. Ind J Clin Biochem, 2012;27(4):322-332.

27) Weijl NI, Elsendoorn TJ, Moison RM, Lentjes EG, Brand R, Berger HM, et al. Non-protein bound iron release during chemotherapy in cancer patients. Clin Sci (Lond). 2004;106:475-84.

28) Grootveld M, Bell JD, Halliwell B et al. Non-transferrin bound iron in plasma or serum from patients with idiopathic hemochromatosis. J Biol Chem. 1989;264:4417-22.

29) van der Heul C, van Eijk HG, Wiltink WF, Leijnse B. The binding of iron to transferrin and to other serum components at different degrees of saturation with iron. Clin Chim Acta.1972;38:347-53.

30) Evans RW, Rafique R, Zarea A, et al. Nature of non-transferrin-bound iron: studies on iron citrate complexes and thalassemic sera. J Biol Inorg Chem. 2008;13(1):57-74. 
31) Pai B, Pai MP, Depczynski J, et al. Nontransferrinbound iron is associated with enhanced Staphylococcus aureus growth in hemodialysis patients receiving intravenous iron sucrose. Am J Nephrol. 2006;26:304-9.

32) Cabantchik ZI, Breuer W, Zanninelli G, Cianciulli P. LPIlabile plasma iron in iron overload. Best Pract Res Clin Haematol. 2005;18:277-87.

33) Gutteridge JMC, Rowley DA, Halliwell B. Superoxidedependent formation of hydroxyl radicals $I$ in the presence of iron salts. Biochem J. 1981;199:263-5.

34) Hershko H, Graham G, Bates GW, Rachmilewitz E. Non specific serum iron in thalassaemia: an abnormal serum iron fraction of potential toxicity. Br J Haematol. 1978;40:255-63.

35) Singh S, Hider RC, Porter JB. A direct method for quantification of non-transferrin-bound iron. Anal Biochem. 1990;186:320-3.

36) Singh S, Hider RC, Porter JB. A direct method for quantification of non-transferrin-bound iron. Anal Biochem. 1990; $186: 320-3$

37) Sharma M, Gohil NK. Interaction of azotobactin with blocking and mobilizing agents in NTBI assay. Mol BioSyst. 2010;6:1941-6.

38) Breuer W, Cabantchik ZI. A fluorescence-based onestep assay for serum non-transferrin-bound iron. Anal Biochem. 2001;299:194-202.

39) Esposito BP, Breuer W, Sirankapracha P, et al. Labile plasma iron in iron overload: redox activity and susceptibility to chelation. Blood. 2003;102(7):2670-7.

40) Jacobs EM, Hendriks JC, van Tits BL, Evans PJ, Breuer W, Liu DY, et al. Results of an international round robin for the quantification of serum non-transferrin-bound iron: need for defining standardization and a clinically relevant isoform. Anal Biochem. 2005;341:241-50.

41) de Swart L, Hendriks JC, van der Vorm LN, et al. Second international round robin for the quantification of serum nontransferrin-bound iron and labile plasma iron in patients with ironoverload disorders. Haematologica 2016, vol 101(1):38-45.

42) Kell DB Iron behaving badly: inappropriate iron chelation as a major contributor to the aetiology of vascular and other progressive inflammatory and degenerative diseases. BMC Medical Genomics 2009, 2:2, 1-79.

43) Sullivan JL. Iron and the sex difference in heart disease risk. Lancet. 1981;1:1293-4.among men. Circulation. 1994;89:969-74.

44) Salonen JT, Nyyssönen K, Korpela H et al. High stored iron levels are associated with excess risk of myocardial infarction in eastern Finnishmen. Circulation. 1992,86(3):803-11.

45) Tuomainen TP, Punnonen K, Nyyssönen K, Salonen JT. Association between body iron stores and the risk of acute myocardial infarction in men. Circulation. 1998, 21;97(15):1461-6.

46) Kiechl S, Willeit J, Egger G, Poewe W, Oberhollenzer F. Body iron stores and the risk of carotid atherosclerosis: prospective results from the Bruneck study. Circulation. 1997;96(10):3300-7.

47) Kiechl S, Willeit J, Egger G, Poewe W, Oberhollenzer F. Body iron stores and the risk of carotid atherosclerosis: prospective results from the Bruneck study. Circulation. 1997, 18;96(10):3300-7.
48) Drüeke T, Witko-Sarsat V, Massy Z, et al. Iron therapy, advanced oxidation protein products, and carotid artery intima-media thickness in end-stage renal disease. Circulation. 2002;106(17):2212-7.

49) Salonen JT, Tuomainen TP, Salonen R, et al. Donation of blood is associated with reduced risk of myocardial infarction. The Kuopio Ischaemic Heart Disease Risk Factor Study. Am J Epidemiol. 1998;148(5):445-51.

50) Meyers DG, Jensen KC, Menitove JE. A historical cohort study of the effect of lowering body iron through blood donation on incident cardiac events. Transfusion. 2002;42(9):1135-9.

51) Syrovatka P, Kraml P, Hulikova K, et al. Iron stores are associated with asymptomatic atherosclerosis in healthy men of primary prevention. Eur J Clin Invest. 2011;41(8):846-53.

52-Duffy SJ, Biegelsen ES, Holbrook M,et al. Iron chelation improves endothelial function in patients with coronary artery disease. Circulation. 2001;103(23):2799-804.

53) Ascherio A, Willett WC, Rimm EB, et al. Dietary iron intake and risk of coronary disease among men. Circulation. 1994 Mar;89(3):969-74.

54) Hunnicutt J, He K, Xun P. Dietary iron intake and body iron stores are associated with risk of coronary heart disease in a metaanalysis of prospective cohort studies. J Nutr. 2014;144(3):359-66.

55) Salonen JT, Nyyssönen K, Korpela H, et al. High stored iron levels are associated with excess risk of myocardial infarction in eastern Finnishmen. Circulation. 1992;86(3):803-11.

56) Carpenter CE, Mahoney AW. Contributions of heme and nonheme iron to human nutrition. Crit Rev Food Sci Nutr. 1992;31(4):333-67.

57) Hunt JR, Roughead ZK. Adaptation of iron absorption in men consuming diets with high or low iron bioavailability. Am J Clin Nutr. 2000;71(1):94-102.

58) Wolk A. Potential health hazards of eating red meat. J Intern Med. 2017;281(2):106-122.

59) Micha R, Michas G, Mozaffarian D. Unprocessed red and processed meats and risk of coronary artery disease and type 2 diabetes--an updated review of the evidence. Curr Atheroscler Rep. 2012;14(6):515-24.

60) Troesch B, Egli I, Zeder C et al. Optimization of a phytase containing micronutrientt powder with low amounts of highlybioavailable iron for in-home fortification of complementary foods. Am J Clin Nutr. 2009;89(2):539-44.

61) Lauffer RB. Exercise as prevention: do the health benefits derive in part from lower iron levels? Med Hypotheses. 1991;35(2):103-7.

62) Xu H, Song Y, Xu J et al. Increased serum ferritin levels are independently associated with carotid atherosclerosis in women. Br J Nutr. 2017;117(11):1623-1630.

63) Kadoglou NPE, Biddulph JP, Rafnsson SB et al. The association of ferritin with cardiovascular and all-cause mortality in community-dwellers: The English longitudinal study of ageing. PLoSOne. 2017,7;12(6):1-13.

64) Madsen JB, Pedersen L, Kidholm CL, Rasmussen LM. Arterial Iron Content Is Increased in Patients with High Plasma Ferritin Levels. J Vasc Res. 2016;53(5-6):301-307. 
65) Klip IT, Voors AA, Swinkels DW, et al. Serum ferritin and risk for new-onset heart failure and cardiovascular events in the community. Eur J Heart Fail. 2017,19(3):348-356.

66) Kartikasari AE, Georgiou NA, Visseren FL, et al. Intracellular labile iron modulates adhesion of human monocytes to human endothelial cells. Arterioscler Thromb Vasc Biol. 2004;24:2257-62

67) Koo SW, Casper KA, Otto KB, et al. Iron chelators inhibit VCAM-1 expression in human dermal microvascular endothelial cells. J Invest Dermatol. 2003;120:871-9.

68) Zhang WJ, Frei B. Intracellular metal ion chelators inhibit TNF alpha-induced SP-1 activation and adhesion molecule expression in human aortic endothelial cells. Free Radic Biol Med. 2003;34:674-82.

69) Derstine JL, Murray-Kolb LE, Yu-Poth S, et al. Iron status in association with cardiovascular disease risk in 3 controlled feeding studies. Am J Clin Nutr. 2003;77:56-62.

70) Knuiman MW, Divitini ML, Olynyk JK, et al. Serum ferritin and cardiovascular disease: a 17-year follow-up study in Busselton Western Australia. Am J Epidemiol. 2003;158:144-9.

71) Sempos CT, Looker AC, Gillum RE,et al. Serum ferritin and death from all causes and cardiovascular disease: the NHANES II Mortality study. Ann Epidemiol.2000;10:441-8.

72) Roghi A, Poggiali E, Duca L, et al. Role of Non-TransferrinBound Iron in the pathogenesis of cardiotoxicity in patients with ST-elevation myocardial infarction assessed by Cardiac Magnetic Resonance Imaging. Int J Cardiol. 2015;199:326-32.

73) De Palma RG, Hayes VW, Chow BK, et al. Ferritin levels, inflammatory biomarkers, and mortality in peripheral arterial disease: a substudy of the Iron (Fe) and Atherosclerosis Study (FeAST) Trial. J Vasc Surg. 2010,51(6):1498-503.

74) Zacharski LR, Shamayeva G, Chow BK. Effect of controlled reduction of body iron stores on clinical outcomes in peripheral arterial disease. Am Heart J. 2011;162(5):949-957.

75) Brissot P, Ropert M, Le Lan C, Lore\#al O. Non-transferrin bound iron: a key role in iron overload and iron toxicity. Biochim Biophys Acta $2012 ; 1820(3): 403-10$.

76) Maas RP, Voets PJ, de Swart L, Swinkels DW. Nontransferrin-bound iron: a promising biomarker in iron overload disorders. Ned Tijdschr Geneeskd. 2013;157(49):A6258.

77) Riško P, Pláteník J, Buchal R et al. The Labile Iron Pool in Monocytes Reflects the Activity of the Atherosclerotic Process in Men With Chronic Cardiovascular Disease. Physiol. Res 2017;66:49-61.

78) Marx JJ, Kartikasari AE, Georgiou NA. Can iron chelators influence the progression of atherosclerosis? Hemoglobin. 2008;32(1-2):123-34.

79) Nagy E., Eaton J. W., Jeney V., Soares M. P., Varga Z., Galajda Z., et al. Red cells, hemoglobin, heme, iron, and atherogenesis. Arterioscler. Thromb. Vasc. Biol. 2010, 30, 1347-1353.

80) Parthasarathy S, Raghavamenon A, Garelnabi MO, Santanam N. Oxidized low-density lipoprotein. Methods Mol Biol. 2010;610:403-17.

81) Skoczynska A, Budzisz E, Trznadel-Grodzka E, Rotsztejn H. Melanin and lipofuscin as hallmarks of skin aging. Postepy Dermatol
Alergol. 2017 ;34(2):97-103. 82) Ehara S, Ueda M, Naruko T, et al. Elevated levels of oxidized low density lipoprotein show a positive relationship with the severity of acute coronary syndromes. Circulation. 2001;103(15):1955-60.

83) Zhang YC, Wei JJ, Wang F, Chen MT, Zhang MZ. Elevated levels of oxidized low-density lipoprotein correlate positively with $\mathrm{C}$-reactive protein in patients with acute coronary syndrome. Cell Biochem Biophys. 2012;62(2):365-72.

84) Butcher MJ, Galkina EV. Phenotypic and functional heterogeneity of macrophages and dendritic cell subsets in the healthy and atherosclerosis-prone aorta. Front Physiol. 2012, 19;3:44.

85) Ley K, Miller YI, Hedrick CC. Monocyte and macrophage dynamics during atherogenesis. Arterioscler Thromb Vasc Biol. 2011;31(7):1506-16.

86) Bobryshev YV, Nikiforov NG, Elizova NV, Orekhov AN. Macrophages and Their Contribution to the Development of Atherosclerosis.Results Probl Cell Differ. 2017;62:273-298.

87) Recalcati S, Locati M, Marini A, et al. Differential regulation of iron homeostasis during human macrophage polarized activation.Eur J Immunol. 2010;40(3):824-35.

88) Cutone A, Rosa L, Lepanto MS et al. Lactoferrin Efficiently Counteracts the Inflammation-Induced Changes of the Iron Homeostasis System in Macrophages. Front Immunol. 2017, $15 ; 8: 705.1-8$.

89) Sindrilaru A, Peters T, Wieschalka S et al. An unrestrained proinflammatory M1 macrophage population induced by iron impairs woundhealing in humans and mice. J Clin Invest. 2011;121(3):985-97.

90) Yuan XM, Anders WL, Olsson AG, Brunk UT. Iron in human atheroma and LDL oxidation by macrophages following erythrophagocytosis. Atherosclerosis. 1996;124(1):61-73.

91) Boyle JJ Heme and haemoglobin direct macrophage Mhem phenotype and counter foam cell formation in areas of intraplaque haemorrhage. Curr Opin Lipidol. 2012;23(5):453-61.

92) Paine A, Eiz-Vesper B, Blasczyk R, Immenschuh S. Signaling to heme oxygenase-1 and its anti-inflammatory therapeutic potential. Biochem Pharmacol. 2010;80(12):1895-903.

93) Kim YM, Pae HO, Park JE et al. Heme oxygenase in the regulation of vascular biology: from molecular mechanisms to therapeutic opportunities. Antioxid Redox Signal. 2011;14(1):137-67.

94) Pechlaner R, Willeit $P$, Summerer $M$, et al. Heme oxygenase-1 gene promoter microsatellite polymorphism is associated with progressive atherosclerosis and incident cardiovascular disease. Arterioscler Thromb Vasc Biol. 2015; 35:229-236.

95) Ryter SW, Choi AM. Targeting heme oxygenase-1 and carbon monoxide for therapeutic modulation ofinflammation. Transl Res. 2016;167(1):7-34.

96) Sullivan JL. Iron in arterial plaque: A modifiable risk factor for atherosclerosis. Biochimica et Biophysica Acta 1790 (2009) 718-723.

97) Rabe E, Guex JJ, Puskas A, Scuderi A et al. Epidemiology of chronic venous disorders in geographically diverse populations: results from the Vein Consult Program. Int Angiol. 2012 ;31(2):105-15

98) Rabe E, Berboth G, Pannier F. Epidemiology of chronic venous diseases. Wien Med Wochenschr.2016, 166(9-10):260-3. 
99) Huriez $\mathrm{C}$ et al. Ulceres de jambes et troubles trophiques d'origines veineuses (donnes tirées de l'etude d'un millier d\#ulcereux hospitalises). Rec Pract 1955; 5: 2703-2721.

100) Shoji T, Niihata K, Fukuma $S$ et al. Both low and high serum ferritin levels predict mortality risk in hemodialysis patients without inflammation Clin Exp Nephrol. 2017;21(4):685-693.

101) Caggiati A, Franceschini M, Heyn R, Rosi C. Skin erythrodiapedesis during chronic venous disorders. J Vasc Surg. 2011;53(6):1649-53.

102) Caggiati A, Rosi C, Casini A, et al. Skin iron deposition characterises lipodermatosclerosis and leg ulcer. Eur J Vasc Endovasc Surg. 2010;40(6):777-82.

103) Cabantchik ZI, Munnich A, Youdim MB, Devos D.Regional siderosis: a new challenge for iron chelation therapy. Front Pharmacol. 2013, 31;4:167

104) Jorizzo JL, White WL, Zanolli MD, et al. Sclerosing panniculitis. A clinicopathologic assessment. Arch Dermatol. 1991;127(4):554-8.

105) Diaz Cascajo C, Borghi S, Weyers W. Panniculitis: definition of terms and diagnostic strategy. Am J Dermatopathol. 2000;22(6):530-49.

106) Miteva M, Romanelli P, Kirsner RS. Lipodermatosclerosis. Dermatol Ther. 2010;23(4):375-88.

107) Choonhakarn C, Chaowattanapanit S, Julanon N Lipodermatosclerosis: a clinicopathologic correlation. Int J Dermatol. 2016;55(3):303-8.

108) Chan CC, Yang CY, Chu CY. Magnetic resonance imaging as a diagnostic tool for extensive lipodermatosclerosis. J Am Acad Dermatol. $2008 ; 58(3): 525-7$.

109) Rumberger JM, Peters T Jr, Burrington C, Green A. Transferrin and iron contribute to the lipolytic effect of serum in isolated adipocytes. Diabetes. 2004;53(10):2535-41.

110) Kim D, Kang WH. Role of dermal melanocytes in cutaneous pigmentation of stasis dermatitis: a histopathologicalstudy of 20 cases. J Korean Med Sci. 2002;17(5):648-54.

111) Chatard H, Dufour $H$. Note on the mixed nature, hematic and melanic, of pigmentations in phlebology. Phlebologie. 1983;36(4):303-6.

112) Granstein RD, Sober AJ. Drug and heavy metal--induced hyperpigmentation. J Am Acad Dermatol. 1981;5(1):1-18.

113) Tsuji T. Experimental hemosiderosis: relationship between skin pigmentation and hemosiderin. Acta Derm Venereol. 1980;60(2):109-14.

114) Thompson J, Pavord S, Lim K. Severe haemosiderin pigmentation after intravenous iron infusion. Intern Med $\mathrm{J}$. 20141;44(7):706-8.

115) Schroeder RL, Gerber JP.A reappraisal of $\mathrm{Fe}(\mathrm{III})$ adsorption by melanin. J Neural Transm 2014 ;121(12):1483-91.

116) Simpson MJ, Wilson JW, Robles FE. Near-infrared excited state dynamics of melanins: the effects of iron content, photo-damage, chemical oxidation, and aggregate size. J Phys Chem A. 2014; 13;118(6):993-1003.

117) Ackerman Z, Seidenbaum M, Loewenthal E, Rubinow A. Overload of iron in the skin of patients with varicose ulcers. Possible contributing role of iron accumulation in progression of the disease. Arch Dermatol. 1988 ;124(9):1376-8.

118) Zamboni P, Izzo M, Fogato L, Carandina S, Lanzara V. Urine hemosiderin: a novel marker to assess the severity of chronic venous disease. J Vasc Surg. 2003;37(1):132-6.

119) Tan J, Smith A, Abisi S, Eastham D, Burnand KG. Tissue and urinary haemosiderin in chronic leg ulcers. Eur J Vasc Endovasc Surg. 2007;34(3):355-60.

120) Yeoh-Ellerton S, Stacey MC. Iron and 8-isoprostane levels in acute and chronic wounds. J Invest Dermatol. 2003;121(4):918-25.

121) Zamboni P, Tognazzo S, Izzo $M$ et al. Hemochromatosis $\mathrm{C} 282 \mathrm{Y}$ gene mutation increases the risk of venous leg ulceration. J Vasc Surg. 2005;42(2):309-14.

122) Zamboni P, Izzo M, Tognazzo S, et al. The overlapping of local iron overload and HFE mutation in venous leg ulcer pathogenesis. Free Radic Biol Med. 2006;40(10):1869-73.

123) Singh AV, Subhashree L, Milani $P$, et al. Interplay of iron metallobiology, metalloproteinases, and FXIII, and role of their gene variants in venous leg ulcer. Int J Low Extrem Wounds. 2010;9(4):166-79.

124) Crawford JM, Lal BK Durán WN, Pappas PJ. Pathophysiology of venous ulceration. J Vasc Surg Venous Lymphat Disord. 2017 Jul;5(4):596-605.

125) Bharath V, Kahn SR, Lazo-Langner A. Genetic polymorphisms of vein wall remodeling in chronic venous disease: a narrative and systematic review. Blood. 2014,21;124(8):1242-50.

126) Brizzio E, Castro M, Narbaitz $M$ et al. Ulcerated hemosiderinic dyschromia and iron deposits within lower limbs treated with a topical application of biological chelator. Veins and Lymphatics 2012;1:e 6,18-26.

127) Mohammadpour M, Behjati M, Sadeghi A, Fassihi A Wound healing by topical application of antioxidant iron chelators: kojic acid and deferiprone. Int Wound J. 2013;10(3):260-4.

128) Krzysciak W, Kowalska J, Kózka M, Papiez MA, Kwiatek WM. Iron content (PIXE) in competent and incompetent veins is related to the vein wall morphology and tissue antioxidant enzymes. Bioelectrochemistry. 2012;87:114-23.

129) Hoy TG, Jacobs A. Ferritin polymers and the formation of haemosiderin. Br J Haematol 1981;49(4):593-602.

130) Ozaki M, Teruyuki $\mathrm{K}$ and Awai M, Iron release from haemosiderin and production of iron-catalysed hydroxyl radicals in vitro. Biochem J 1988;250:589-595. DOI: https://doi.org/10.1042/ bj250058.

131) Shoden A, Gabrio BW, Finch CA. The relationship between ferritin and hemosiderin in rabbits and man. J Biol Chem 1953;204(2):823-30.

132) Shoden A, Gabrio BW, Finch CA. Quantitative fractionation of tissue ferritin and hemosiderin. J Biol Chem 1953 Oct;204(2):815-21.

133) Saito H. Metabolism of iron stores. Nagoya J. Med. Sci. 2014;76:235-254.

134) Saito H, Tomita A, Ohashi H, Maeda H, Hayashi H, Naoe T. Determination of ferritin and hemosiderin iron in patients with 
M Izzo, V Gasbarro, V Coscia - The role of free iron in cardiovascular diseases. Part II

normal iron stores and iron overload by serum ferritin kinetics. Nagoya J Med Sci, 2012;74(1-2):39-49.

135) Adams BD, Lazova R, Andrews NC, Milstone LM. Iron in skin of mice with three etiologies of systemic iron overload. J Invest Dermatol. 2005;125(6):1200-5.

136) Milstone LM, Hu RH, Dziura JD, Zhou J. Impact of epidermal desquamation on tissue stores of iron. J Dermatol Sci. 2012;67(1):9-14.

137) Wright JA, Richards T, Srai SK. The role of iron in the skin and cutaneous wound healing. Front Pharmacol. 2014;10;5:156;1-8.

138) Northcutt AD, Tschen JA.The routine use of iron stain for biopsies of dermatoses of the legs. J Cutan Pathol. 2015;42(10):717-21.
139) Muñoz-Bravo C, Gutiérrez-Bedmar M, Gómez-Aracena $\mathrm{J}$ et al. Iron: protector or risk factor for cardiovascular disease? Still controversial. Nutrients. 2013;5(7):2384-404.

140) Schulz-Geske S, Erdmann K, Wong RJ et al. Molecular mechanism and functional consequences of lansoprazolemediated heme oxygenase-1induction. World J Gastroenterol. 2009;15(35):4392-401.

141) Linkermann A, Stockwell BR, Vanden Berghe T. Heavy Metal Suicide. Am J Physiol Renal 2017, In Press. 142) Hoekstra KA, Godin DV, Cheng KM. Protective role of heme oxygenase in the blood vessel wall during atherogenesis. Biochem Cell Biol. 2004;82(3):351-9.

143) Immenschuh S and Schröder H. Heme oxygenase-1 and cardiovascular disease. Histol Histopathol 2006;21:679-685. 